\title{
Author Correction: Computational Analysis of the Molecular Mechanism of RamR Mutations Contributing to Antimicrobial Resistance in Salmonella enterica
}

\author{
Yen-Yi Liu ${ }^{1} \&$ Chih-Chieh Chen $\mathbb{D}^{2,3,4,5}$ \\ Correction to: Scientific Reports https://doi.org/10.1038/s41598-017-14008-5, published online 17 October 2017 \\ In the original version of this Article, there was a repeated error in which " $a c r A B$ " was incorrectly written as \\ " $\operatorname{arc} A B$ ".
}

The original version of this Article also contained an error in the Materials and Methods.

“The steepest descent algorithm ${ }^{30}$ was used for structural optimization (energy minimization), and $\mathrm{PyMO}^{31}$ was used for all three-dimensional (3D) structures and charge distribution presentation."

now reads:

“The steepest descent algorithm ${ }^{30}$ was used for structural optimization (energy minimization), and PyMOL ${ }^{31}$ was used for all three-dimensional (3D) structures and charge distribution presentation."

These errors have now been corrected in the HTML and PDF versions of this Article.

(i) Open Access This article is licensed under a Creative Commons Attribution 4.0 International cc) License, which permits use, sharing, adaptation, distribution and reproduction in any medium or format, as long as you give appropriate credit to the original author(s) and the source, provide a link to the Creative Commons license, and indicate if changes were made. The images or other third party material in this article are included in the article's Creative Commons license, unless indicated otherwise in a credit line to the material. If material is not included in the article's Creative Commons license and your intended use is not permitted by statutory regulation or exceeds the permitted use, you will need to obtain permission directly from the copyright holder. To view a copy of this license, visit http://creativecommons.org/licenses/by/4.0/.

(C) The Author(s) 2018

\footnotetext{
${ }^{1}$ Institute of Population Health Sciences, National Health Research Institutes, Miaoli, 35053, Taiwan. ${ }^{2}$ Institute of Medical Science and Technology, National Sun Yat-sen University, Kaohsiung, 80424, Taiwan. ${ }^{3}$ Medical Science and Technology Center, National Sun Yat-sen University, Kaohsiung, 80424, Taiwan. ${ }^{4}$ Rapid Screening Research Center, National Sun Yat-sen University, Kaohsiung, 80424, Taiwan. ${ }^{5}$ General Institute of Clinical Medicine, Kaohsiung Medical University, Kaohsiung, 80708, Taiwan. Correspondence and requests for materials should be addressed to C.-C.C. (email: chieh@imst.nsysu.edu.tw)
} 